\title{
Hierarchical Porous Carbon Electrodes with Sponge-Like Edge Structures for the Sensitive Electrochemical Detection of Heavy Metals
}

\author{
Jongmin Lee, Soosung Kim and Heungjoo Shin *(1) \\ Department of Mechanical Engineering, Ulsan National Institute of Science and Technology (UNIST), \\ 50 UNIST-gil, Eonyang-eup, Ulju-gun, Ulsan 44919, Korea; gmcljw@unist.ac.kr (J.L.); \\ rnfnr225@gm.gist.ac.kr (S.K.) \\ * Correspondence: hjshin@unist.ac.kr; Tel.: +82-52-217-2315
}

check for updates

Citation: Lee, J.; Kim, S.; Shin, H. Hierarchical Porous Carbon Electrodes with Sponge-Like Edge Structures for the Sensitive Electrochemical Detection of Heavy Metals. Sensors 2021, 21, 1346. https://doi.org/10.3390/s21041346

Academic Editor: Ivo Allegrini

Received: 24 December 2020

Accepted: 12 February 2021

Published: 14 February 2021

Publisher's Note: MDPI stays neutral with regard to jurisdictional claims in published maps and institutional affiliations.

Copyright: (c) 2021 by the authors. Licensee MDPI, Basel, Switzerland. This article is an open access article distributed under the terms and conditions of the Creative Commons Attribution (CC BY) license (https:/ / creativecommons.org/licenses/by/ $4.0 /)$.

\begin{abstract}
This article presents the development of a highly sensitive electrochemical heavy metal sensor based on hierarchical porous carbon electrodes with sponge-like edge structures. Micrometerscale hierarchical nanoporous carbon electrodes were fabricated at a wafer-scale using cost-effective batch microfabrication technologies, including the carbon microelectromechanical systems technology and oxygen plasma etching. The sponge-like hierarchical porous structure and sub-micrometer edges of the nanoporous carbon electrodes facilitate fast electron transfer rate and large active sites, leading to the efficient formation of dense heavy metal alloy particles of small sizes during the preconcentration step. This enhanced the peak current response during the square wave anodic stripping voltammetry, enabling the detection of $\mathrm{Cd}(\mathrm{II})$ and $\mathrm{Pb}(\mathrm{II})$ at concentrations as low as 0.41 and $0.7 \mu \mathrm{g} \mathrm{L}^{-1}$, respectively, with high sensitivity per unit sensing area $\left(\mathrm{Cd}: 109.45 \mathrm{nA} \mathrm{\mu g}{ }^{-1} \mathrm{~L} \mathrm{~mm}^{-2}\right.$,

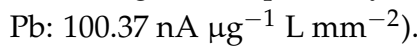

Keywords: heavy metal sensor; hierarchical nanoporous carbon; sponge-like edge; sensitivity; CMEMS

\section{Introduction}

Heavy metal ions can accumulate in the human body and cause serious damage to organs. For example, cadmium and lead cause disorders of the nervous system, kidney, liver, and bones, even at a small quantity [1]. The standard guidelines of the US Environmental Protection Agency (EPA) restrict the concentration of cadmium and lead in drinking water at 5 and 15 ppb, respectively [2]. The well-developed heavy metal analysis methods based on spectroscopy, such as inductively coupled plasma mass spectrometry, atomic absorption spectroscopy, and X-ray fluorescence (XRF) spectroscopy [3-5], can facilitate the detection of heavy metals at concentrations as low as parts per trillion in a laboratory [6]. However, these laboratory techniques require long analysis times and skilled personnel [7,8]. In addition, field detection is limited because of the bulky equipment size. Although portable XRF spectrometers are relatively free from these limitations, their limit of detection (LOD) is not sufficient for detecting heavy metal ions at parts per billion levels [9].

Owing to the simple configuration and small size, electrochemical and colorimetric analysis methods have been adopted for on-site heavy metal detection. In addition, these methods facilitate a more sensitive detection of multiple heavy metal ions at a lower cost, as compared to that of the portable XRF spectrometry [10-12]. Recently, Ying Gan et al. reported the successful detection of cadmium at concentrations as low as $1.12 \mathrm{ppb}$, using a colorimetric method; this concentration is much lower than the EPA standard for cadmium concentration in drinking water [13]. However, the colorimetric method still has limitations, such as a relatively complex sample preparation step and low sensitivity in the detection of multiple heavy metal ions, when compared to the electrochemical method [14]. 
Square wave anodic stripping voltammetry (SWASV) has been widely used for the electrochemical detection of heavy metals because multiple heavy metals can be distinguished with high sensitivity, according to their characteristic oxidation potential $[15,16]$. SWASV consists of two steps: (i) a preconcentration step in which the heavy metal ions in the analyte are concentrated by electrodeposition and (ii) an anodic removal step in which the electrodeposited metal alloy is oxidized to generate a peak current signal for each metal.

In early studies, mercury was employed as the electrode material for the anodic stripping method-based heavy metal sensors because it facilitates efficient amalgam formation, leading to high sensitivity and good reproducibility [17-19]. However, the toxicity of the mercury has limited its further application in heavy metal sensor electrodes, and bismuth has consequently received attention as a non-toxic electrode material [20,21]. For an electrochemical electrode of a heavy metal sensor, a nanoporous structure is generally used to enlarge the adsorption sites and improve the diffusion and local concentration of the target ions [22,23]. In particular, carbon-based porous electrodes are widely used in the bismuth-modified heavy metal sensors because of their good conductivity among the porous electrode materials, wide potential window, and low cost $[20,21,24]$. In addition, when the porous electrode has a hierarchical architecture, the electrode provides excellent advantages. For example, the macropores and mesopores enhance the diffusion of the electrochemical species into the nanopores; the adsorption sites are increased, facilitating excellent physical and chemical adsorption of metal ions; and the reaction kinetics is improved due to the small diffusion length in the 3D porous structure [25-27]. Previously, hierarchical nanoporous carbon electrodes fabricated by eco-friendly methods using biomass were developed to improve the heavy metal adsorption $[25,26,28]$. The biomass-induced nanoporous electrode-based heavy metal sensor allowed the sensitive detection of heavy metal ions at low concentrations.

In this study, we developed a highly sensitive heavy metal sensor based on patternable hierarchical nanoporous carbon electrode. The disk-shaped carbon electrode with hierarchical sponge-like porous networks was prepared by the fabrication technology of carbon microelectromechanical systems (C-MEMS) and microwave $\mathrm{O}_{2}$ plasma etching, which facilitated 6-inch wafer-scale batch fabrication, ensuring cost-effective sensor production. C-MEMS is capable of generating glassy carbon micro/nanostructures by pyrolyzing photosensitive polymer structures pre-patterned by using various lithography technologies, including photolithography and e-beam lithography $[29,30]$. The C-MEMS-based glassy carbon is a good electrode material for electrochemical analysis, owing to its advantageous properties, such as high thermal stability, excellent electrochemical stability, and a wide potential window [31]. For this reason, the glassy carbon microelectrodes have been widely used in a variety of electrochemical analysis applications, such as biomolecule detection [32,33], bacterial sensing [34], cell sensing [35], and heavy metal detection [36]. In addition, the glassy carbon has good corrosion resistance, allowing the heavy metal sensor to operate stably during the preconcentration and stripping steps in SWAV. In addition to the patternability of the C-MEMS-based microelectrode, nanowire forest-like porous surface can be formed in a facile manner, by treating polymer precursors, using $\mathrm{O}_{2}$ plasma prior to pyrolysis [37]. In this study, a hierarchical sponge-like porous networks could be formed via microwave $\mathrm{O}_{2}$ plasma, which generates high plasma density with low ion bombardment energy [38]. The sponge-like edge structure, as well as the large surface area derived from the hierarchical nanostructure, enabled efficient and conformal electrodeposition of the metals in the preconcentration step, leading to high sensitivity in the simultaneous detection of dual heavy metal ions, $\mathrm{Cd}$ (II) and $\mathrm{Pb}$ (II). In addition, the hierarchical nanoporous electrode exhibited a large current density (peak current/unit sensing area), facilitating heavy metal detection with a low LOD, even with a micrometer sized electrode. In this study, the effect of the hierarchical porous architecture on the heavy metal sensing was analyzed by comparing the preconcentration behaviors and the corresponding anodic stripping current signals of $\mathrm{Cd}$ and $\mathrm{Pb}$ ions, using carbon electrodes with different surface porosities. The reliability of the patternable hierarchical nanoporous 
carbon electrode-based heavy metal sensor was verified by using tap water spiked with heavy metal ions.

\section{Materials and Methods}

\subsection{Materials}

A negative photoresist (SU-8 2025, Kayaku Advanced Materials, Inc., Westborough, MA, USA) was used as the precursor for the pyrolyzed carbon electrode, while a positive photoresist (AZ 40 XT, Merk KGaA, Darmstadt, Germany) was used as the mask material for the insulation layer patterning. Potassium ferrocyanide $\left(\mathrm{K}_{4} \mathrm{Fe}(\mathrm{CN})_{6}\right)$, potassium chloride $(\mathrm{KCl})$, potassium sulfate $\left(\mathrm{K}_{2} \mathrm{SO}_{4}\right)$, and standard solutions of $\mathrm{Cd}$ and $\mathrm{Pb}$ were purchased from Sigma-Aldrich (St. Louis, MO, USA). The standard solution of bismuth was purchased from Kanto Chemical Co., Inc. (Tokyo, Japan). Acetic acid (glacial, 99.7\%) was purchased from Samchun Chemical Co. (Seoul, Korea). Sodium acetate trihydrate was purchased from Junsei Chemical Co., Ltd. (Tokyo, Japan). The buffered oxide etch (BOE) solution (JT Baker) was purchased from Fisher scientific (Waltham, MA, USA). Tap water was obtained from waterworks in Ulsan, South Korea.

\subsection{Fabrication of the Hierarchical Nanoporous Carbon Electrode with Sponge-Like Edge Structures}

Hierarchical nanoporous-carbon-structure-based sensors of heavy metals were fabricated in a controllable manner through C-MEMS and $\mathrm{O}_{2}$ microwave plasma etching. The dimensions and geometries of the fabricated structures were inspected, using a surface profiler (P6, KLA Corporation, Milpitas, CA, USA) and a scanning electron microscope (Quanta200 FE-SEM, FEI Company, Hillsboro, OR, USA). First, $25 \mu \mathrm{m}$ thick photoresist structures were patterned using the SU-8 2025 negative photoresist by UV-lithography on top of a thermally oxidized 6-inch silicon wafer, as shown in Figure 1A-D. Then, the surface of the photoresist was subjected to $\mathrm{O}_{2}$ microwave plasma etching (V15-G, KAMI, Linden, Germany), to controllably form a structure with surface porosity and sponge-like networks, as shown in Figure 1E. In this study, the surface porosity was controlled by changing the microwave plasma etching time, while the flow rate $\left(\mathrm{O}_{2} 100 \mathrm{sccm}\right)$, plasma power $(500 \mathrm{~W})$, and chamber pressure (60 mTorr) were fixed. After the oxygen-plasma-etching process, the photoresist structures were pyrolyzed in a vacuum furnace (DMTF15/145-400, Daemyoung Enterprise Co., Ltd., Gwangmyeong-si, Korea), to convert the polymer structures into carbon electrodes, while maintaining the surface porosity. To enhance the electrical conductivity, the pyrolyzed porous carbon electrodes were subsequently subjected to a rapid thermal-annealing process (KVR-6000, Korea Vacuum Tech., Ltd., Gimpo-si, Korea) at $1000{ }^{\circ} \mathrm{C}$, as described in our previous report [39]. The nanoporous carbon electrodes were finally insulated with a silicon dioxide layer via plasma-enhanced chemical vapor deposition (PEH-600, SORONA Inc., Anseong-si, Korea), as shown in Figure 1G. The active sensing area of the nanoporous carbon electrodes was exposed through UV lithography and BOE wet-etching processes, as shown in Figure 1H-L.

\subsection{Electrochemical Characterization of Hierarchical Nanoporous Carbon Electrodes}

The electrochemical properties of the prepared nanoporous carbon electrodes with different surface morphologies were characterized by cyclic voltammetry (CV) and SWASV. A three-electrode system was used for all the electrochemical experiments; a commercial $\mathrm{Ag} / \mathrm{AgCl}$ reference electrode (RE-1B, ALS Co., Ltd., Tokyo, Japan), a platinum wire, and the prepared nanoporous carbon electrodes were used as the reference, counter, and working electrode, respectively. The surface area of the electrode was determined electrochemically through $\mathrm{CV}$ in a $0.2 \mathrm{M} \mathrm{K}_{2} \mathrm{SO}_{4}$ solution, by scanning the working electrode from 0 to $0.8 \mathrm{~V}$ vs. an $\mathrm{Ag} / \mathrm{AgCl}$ electrode. The electrochemical reactivity of the electrode surface was characterized, using $\mathrm{CV}$ of $10 \mathrm{mM} \mathrm{K}_{4} \mathrm{Fe}(\mathrm{CN})_{6}$ in $0.5 \mathrm{M} \mathrm{KCl}$. The heavy metal alloy of bismuth, cadmium, and lead was electrodeposited at $-1.4 \mathrm{~V}$, to analyze the effect of the morphology of the electrode surface on the preconcentration behaviors. These electrochemical charac- 
terizations were performed, using a multi-potentiostat (CHI 1020, CH Instruments, Inc., Austin, TX, USA). The heavy-metal-detection capability of nanoporous carbon electrodes was evaluated by SWASV, using a potentiostat (Modulab XM MTS, Solatron Analytical, Hampshire, UK). Bismuth and the target heavy metals were electrodeposited in the form of an alloy on the nanoporous carbon electrodes at a reduction potential of $-1.4 \mathrm{~V}$ vs. an $\mathrm{Ag} / \mathrm{AgCl}$ electrode for $300 \mathrm{~s}$. Then, the electrodeposited alloy was stripped with a square wave of $15 \mathrm{~Hz}$ frequency, $25 \mathrm{mV}$ pulse amplitude, and $5 \mathrm{mV}$ step potential; this resulted in anodic stripping current signals. The nanoporous carbon electrodes were electrochemically cleaned by applying $0.2 \mathrm{~V}$ vs. $\mathrm{Ag} / \mathrm{AgCl}$ reference electrode for $60 \mathrm{~s}$ in $0.1 \mathrm{M} \mathrm{NaAc}$ buffer solution between each measurement. Tap water from Ulsan, South Korea, was used to validate the heavy metal sensor in the analysis of real samples. The tap water was spiked with $\mathrm{Cd}$ and $\mathrm{Pb}$ ions, and the solution was diluted with $0.1 \mathrm{M} \mathrm{NaAc}$ buffer at a 1:1 ratio. The composition of the carbon electrodes, according to $\mathrm{O}_{2}$-plasma-etching time, was analyzed by using X-ray photoelectron spectroscopy (XPS; ESCALAB 250XI, Thermo Fisher Scientific Inc., Waltham, MA, USA). The compositions of tap-water samples were analyzed by ICP-MS (Agilent 7700s, Agilent Technologies, Inc., Santa Clara, CA, USA).

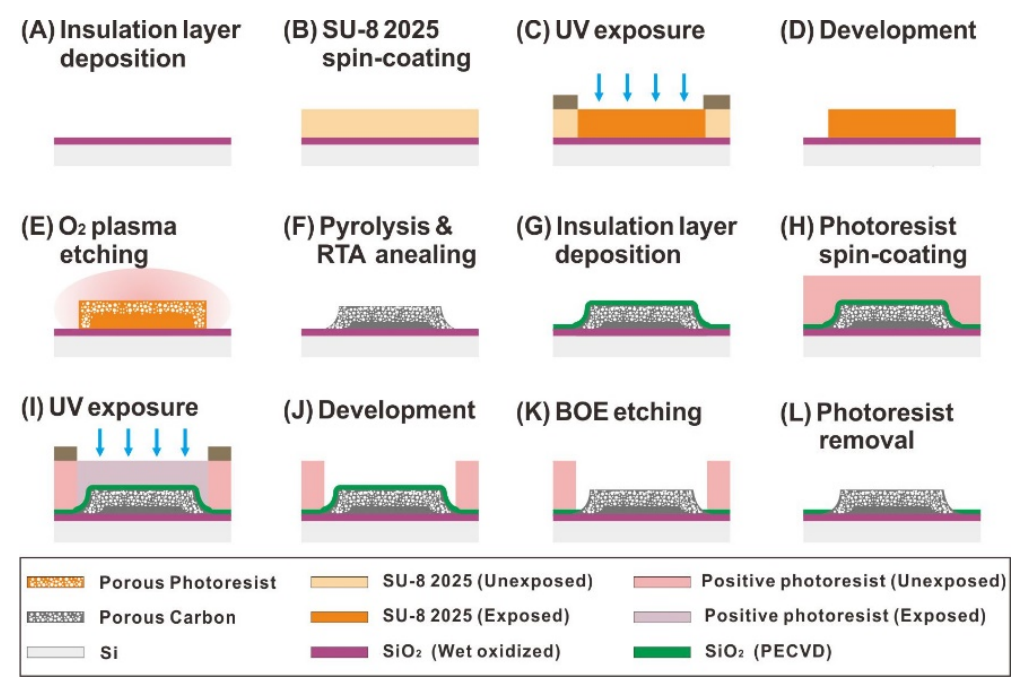

Figure 1. Schematic of the fabrication steps for hierarchical nanoporous carbon electrodes (PR, photoresist; RTA, rapid thermal annealing; BOE, buffered oxide etch).

\section{Results and Discussion}

\subsection{Morphology of the Nanoporous Carbon Electrode with a Sponge-Like Edge Structure}

Three types of carbon electrodes with different porosities and surface morphologies are categorized as bare carbon (BC), porous carbon (PC), and hierarchical porous carbon (HPC), based on the surface porosity achieved depending on the $\mathrm{O}_{2}$-plasma-etching time (Figure 2A). In this study, microwave plasma was used to form nanoporous spongelike networks on the surface of SU-8 photoresist structures. This negative photoresist polymer contains antimony ions that have a high etching resistance to $\mathrm{O}_{2}$ plasma, and these ions act as etch masks. In addition to this self-mask material, the difference between the etching rates of the aromatic and aliphatic parts of the photoresist also causes the formation of a nanoporous surface $[37,40]$. Furthermore, the microwave plasma-etching process generates etching species with low ion bombardment energy, leading to isotropic etching. Therefore, sponge-like nanoporous networks consisting of pores and narrow edge structures are formed instead of vertically aligned nanostructures, as illustrated in the sectional schematics of the PC and HPC electrodes (Figure 2A). As the plasma-etching proceeds, the polymer surface is removed progressively, and, thus, the top macropore size increases and additional nanoporous layers are formed below the top macropores, leading to the formation of sponge-like hierarchical porous networks, as shown in the sectional 
view of the HPC electrode in Figure 2A. The HPC, PC, and BC electrodes were prepared in the form of disks of $400 \mu \mathrm{m}$ diameter, as shown in Figure 2B.
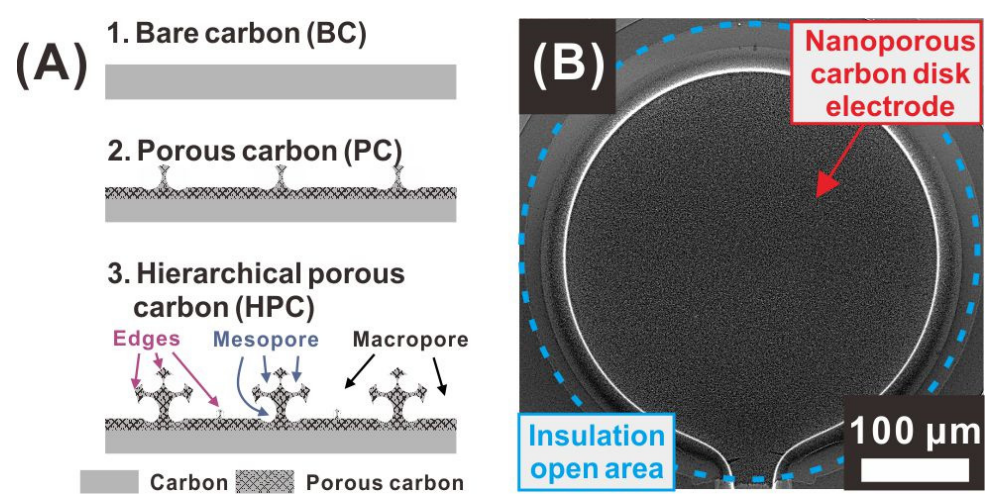

Figure 2. (A) Schematic sectional views of nanoporous carbon electrodes, according to their porosity. (B) Scanning electron microscopy image of a hierarchical porous carbon (HPC) disk electrode.

The surface morphology of each electrode was observed by scanning electron microscopy (SEM). Before the $\mathrm{O}_{2}$-plasma-polymer-etching process, the pyrolyzed carbon electrode (BC electrode) exhibited a smooth surface without any micro/nanostructures, as shown in Figure 3A. The PC electrode obtained by pyrolyzing a negative photoresist structure treated with an $\mathrm{O}_{2}$ plasma process for $300 \mathrm{~s}$ exhibited nanoscale edge networks, with micrometer-sized cavities, as shown in Figure 3B. A longer $\mathrm{O}_{2}$-plasma-etching process (900 s) resulted in the HPC electrode with a 3D sponge-like hierarchical nanoporous network, as shown in Figure 3C. This HPC electrode exhibited the largest cavity (50 nm to $2 \mu \mathrm{m}$ ) at the top surface and additional smaller porous networks formed below the pre-formed larger pore structures, leading to a higher surface area, compared to those of the PC and BC electrodes, as demonstrated in the ensuing section.

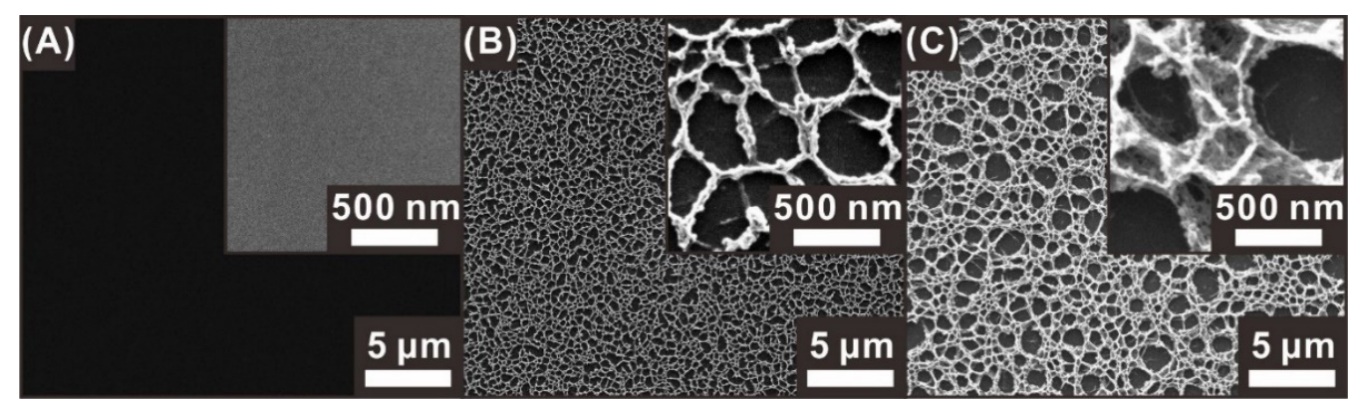

Figure 3. SEM images of carbon electrodes with different surface porosities formed depending on the $\mathrm{O}_{2}$-plasma-etching time: (A) bare carbon (BC) electrode (no plasma etching process), (B) porous carbon (PC) electrode (300 s plasma etching), and (C) HPC electrode (900 s plasma etching).

\subsection{Effect of the Electrode Surface Properties on the Heavy Metal Detection}

The effect of the plasma-etching time-dependent nanoporous morphology on the electrochemically active surface area (EASA) of the carbon electrodes was evaluated by using their double-layer capacitances calculated from $\mathrm{CVs}$, as described by the following:

$$
\mathrm{EASA}=\mathrm{C}_{\mathrm{dl}} / \mathrm{C}_{\mathrm{s}}
$$

where $C_{\mathrm{dl}}$ is the double-layer capacitance, and $C_{S}$ is the specific capacitance of the standard materials [41,42]. First, the CVs were collected from a $0.2 \mathrm{M}$ potassium sulfate solution at various scan rates, as shown in Supplementary Materials Figure S1. Then, the double-layer capacitance, which corresponds to the slope of the linear regression curve of the difference between the currents at the middle of the potential window $\left(\left(\mathrm{i}_{\text {anodic }}, 0.4 \mathrm{~V}-\mathrm{i}_{\text {cathodic }}\right.\right.$ 
$0.4 \mathrm{~V}) / 2$ ) versus the scan rate (Figure $4 \mathrm{~A}$ ), was determined. The specific capacitance of the standard materials was assumed to be the same for all electrodes. Thus, the relative ratios of the EASA of the nanoporous electrodes (PC and HPC), compared to that of the BC electrode were estimated (Figure 4B), according to the linear relationship between the EASA and double-layer capacitance. The PC and HPC electrodes exhibited 4.6 and 12.8 times greater EASA than that of the BC electrode, respectively. As mentioned earlier, the hierarchical porous networks were well-developed in the HPC electrode, leading to the largest surface area.
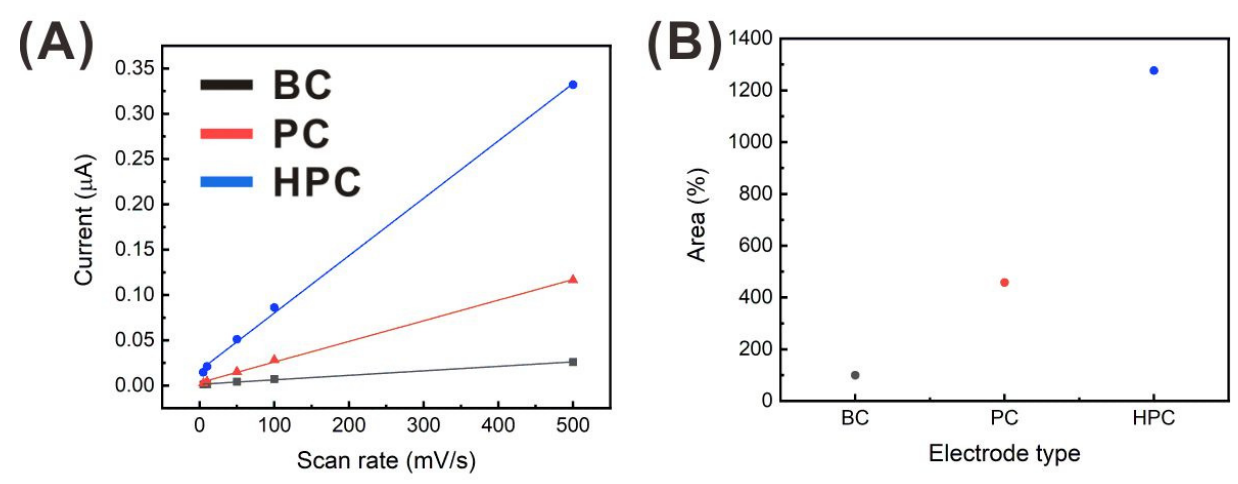

Figure 4. (A) Capacitive current difference at the middle of the potential window, according to the scan rate, and (B) the corresponding electrochemically active surface area (EASA) ratios of the HPC and PC electrodes, compared to that of the BC electrode.

The electrochemical properties of the carbon electrodes were characterized by using $\mathrm{CV}$ of $10 \mathrm{mM}$ ferrocyanide in $0.5 \mathrm{M} \mathrm{KCl}$, as shown in Figure $5 \mathrm{~A}$. As the porosity increased, the peak-to-peak separation $\left(\Delta \mathrm{E}_{\mathrm{p}}\right)$ decreased, indicating enhanced surface reactivity. However, the diffusion-limited current did not change significantly and even decreased with the porosity, although the EASA values of the nanoporous electrodes were significantly higher than that of the BC electrode. This is because most of the electrochemical species are consumed at the top of the nanoporous surface, owing to the efficient electron transfer rate, and the deeper pore regions far from the bulk solution do not participate in the redox reaction [43]. In addition, it should be emphasized that the thickness of the carbon electrodes decreased with the $\mathrm{O}_{2}$-plasma-etching time (thickness: BC, $4.5 \mu \mathrm{m}$; PC, $3.7 \mu \mathrm{m}$; $\mathrm{HPC}, 3.4 \mu \mathrm{m})$, and, thus, the overall surface area was reduced.
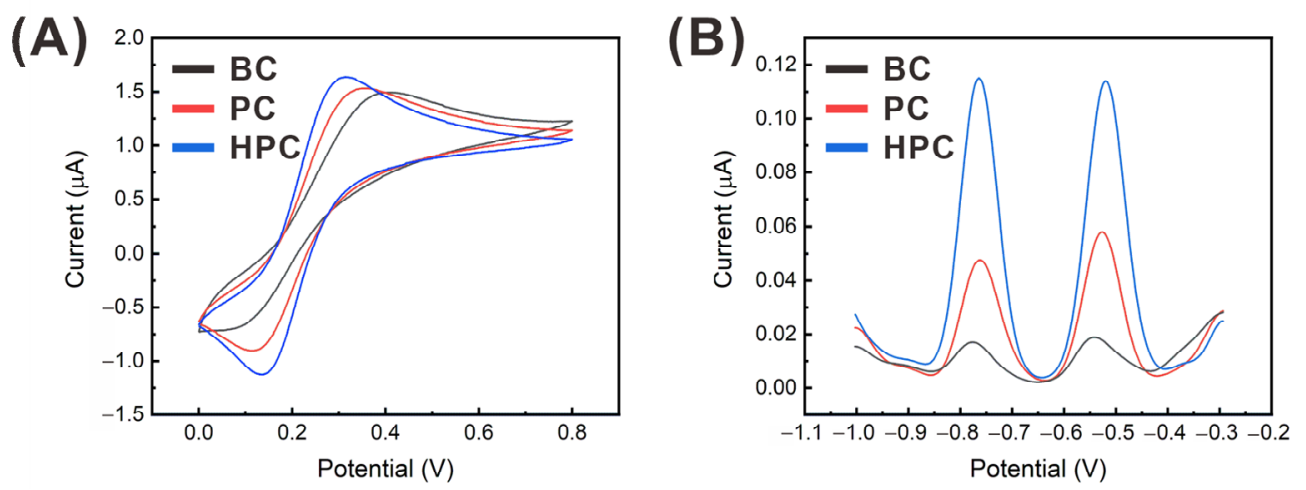

Figure 5. (A) Cyclic voltammograms of $10 \mathrm{mM}$ ferrocyanide in $0.5 \mathrm{M} \mathrm{KCl}$ at the scan rate of $0.05 \mathrm{~V} / \mathrm{s}$. (B) Square wave anodic stripping voltammetry (SWASV) current signals from $10 \mu \mathrm{g} \mathrm{L}^{-1}$ of each of cadmium and lead, along with $400 \mu \mathrm{g} \mathrm{L}^{-1}$ of bismuth in a NaAc buffer measured by using the BC, PC, and HPC electrodes.

The effect of the surface porosity of the carbon electrode on the SWASV-based heavy metal detection was evaluated with $10 \mu \mathrm{g} \mathrm{L}^{-1}$ of each of cadmium and lead, and $400 \mu \mathrm{g} \mathrm{L}^{-1}$ 
of bismuth in a NaAc buffer solution. The stripping peak currents were observed between -0.7 and $-0.8 \mathrm{~V}$ for cadmium and -0.45 to -0.6 for lead, and the current signals increased with increasing the porosity, as shown in Figure 5B. Compared to the increase in the electrochemical performance with the porosity demonstrated by the CV tests, the SWASV peak current was more significantly enhanced. For further analyzing the reason for the enhanced sensing performance of the HPC electrode, the preconcentration behaviors were investigated according to the surface morphology.

In the preconcentration step, the deposition behavior of the heavy metal ions is affected by the surface morphology of the electrode, and this behavior strongly affects the anodic current signals in the detection of heavy metal ions. Thus, the effect of the porous surface morphology on the heavy metal detection was investigated by studying the electrodeposition behavior of the alloys of cadmium and lead with bismuth on the three carbon electrodes (BC, PC, and HPC). For a clear observation of the heavy metal alloy, excessive amounts of cadmium $\left(10 \mathrm{mg} \mathrm{L}^{-1}\right)$ and lead $\left(10 \mathrm{mg} \mathrm{L}^{-1}\right)$ were electrodeposited on each type of the electrode for $30 \mathrm{~min}(-1.4 \mathrm{~V}$ vs. $\mathrm{Ag} / \mathrm{AgCl}$ electrode), without an anodic stripping step. The bismuth concentration was fixed at the heavy metal detection condition (400 $\mu \mathrm{g} \mathrm{L}^{-1}$ in the NaAc buffer). The heavy metal alloy deposition differed in shape and distribution, depending on the surface porosity of the electrodes, as shown in SEM images and corresponding energy-dispersive X-ray spectroscopy (EDS) mapping. The BC electrode exhibited relatively large heavy metal alloy islands that were irregularly distributed at a low density (Figure 6A and Supplementary Materials Figure S2). The EDS mapping exhibited a negligible amount of $\mathrm{Bi}$, because excessive amount of $\mathrm{Pb}$ and $\mathrm{Cd}$ were deposited as mentioned above. In contrast, metal alloy particles were deposited at a significantly higher density on the PC electrode surface. Specifically, the metal particles were mainly located on the edges of the macropores, as shown in Figure 6B and Supplementary Materials Figure S3. The HPC also exhibited similar behavior as that of the PC electrode, but the metal particles were distributed deeper in the hierarchical nanoporous network with smaller particle sizes than those on the PC electrode (Figure 6C and Supplementary Materials Figure S4). During the electrodeposition, protruded features of the electrode function as more electrochemically active sites, owing to the enhanced local electric field, leading to more efficient deposition on them than on the planar electrode region [22,23]. Therefore, metal particles were deposited along the sponge-like edge networks of the nanoporous carbon electrode surface, resulting in conformal and dense particle deposits. In addition, as the porosity increased, the particle size decreased due to the enlarged active sites under the fixed metal ion concentration condition. Therefore, this conformal and dense deposition of heavy metal alloy particles enhanced the anodic-stripping current signal. Moreover, the smaller metal particles formed on the HPC electrode facilitated more efficient anodic stripping, owing to the larger surface-to-volume ratio of the particle.

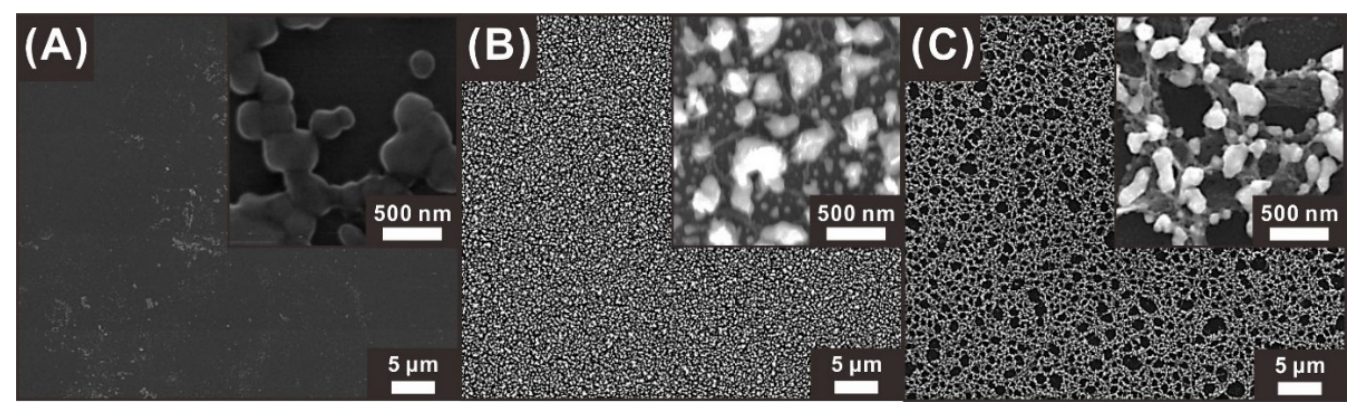

Figure 6. SEM images of (A) BC, (B) PC, and (C) HPC electrodes with the electrodeposited heavy metal alloys (Cd, $\left.10 \mathrm{mg} \mathrm{L}^{-1} ; \mathrm{Pb}, 10 \mathrm{mg} \mathrm{L}^{-1} ; \mathrm{Bi}, 400 \mu \mathrm{g} \mathrm{L}^{-1}\right)$.

The XPS measurements were carried out to analyze the composition change of the pyrolyzed carbon electrodes, according to $\mathrm{O}_{2}$-plasma-etching time. In the $\mathrm{C} 1$ s region, no significant difference in peak intensity at $283.7 \mathrm{eV}$, which represents aromatic and aliphatic 
carbons, was shown between BC, PC, and HPC electrodes (Supplementary Materials Figure $\mathrm{S} 5 \mathrm{~A})$. In contrast, the PC and HPC electrodes show higher peak intensities compared to the $\mathrm{BC}$ electrode in the O1s spectra region (Supplementary Materials Figure S5B). Therefore, the atomic ratio of $\mathrm{O} / \mathrm{C}$ increases with the oxygen-plasma-etching time. The reason for this can be inferred from the previous study on the oxygen-plasma-treated SU-8, using XPS by Lim et al. [38]: As the $\mathrm{O}_{2}$ plasma etching proceeds, the atomic ratio of $\mathrm{O} / \mathrm{C}$ increases due to the partial oxidation on the SU-8 surface [44]. Thus, the enhancement of the adsorption of the heavy metal ions in the oxygen-plasma-treated carbon can be attributed to the evolved oxygen-containing functional groups [26].

In conclusion, the increased EASA of the hierarchical nanoporous electrode did not significantly enhance the Faradaic reaction, but the well-developed networks of sponge-like edges and enhanced oxygen functional group facilitated the formation of dense small metal alloy particles, leading to enhanced heavy-metal-detection capability.

\subsection{Optimization of the Preconcentration Conditions}

As stated in the previous section, the HPC exhibited the best heavy-metal-sensing capability, owing to its enhanced surface reactivity and adsorption capability. Therefore, the HPC electrode was used for further heavy-metal-sensing studies. First, the effects of preconcentration conditions, including the $\mathrm{pH}$, potential, duration, and $\mathrm{Bi}$ concentration on the anodic stripping current signal, were analyzed, using the HPC electrode. The maximum stripping current response was obtained at $\mathrm{pH} 4.5$ for both the cadmium and lead ions, as shown in Supplementary Materials Figure S6A. The peak current response increased as the HPC electrode was biased at higher magnitudes of the negative potential and decreased beyond $-1.4 \mathrm{~V}$, because of the adverse effect of hydrogen evolution (Supplementary Materials Figure S6B). With the $\mathrm{pH}$ and potential fixed at 4.5 and $-1.4 \mathrm{~V}$, respectively, the duration and Bi concentration of the preconcentration step were optimized. The current signals corresponding to both the ions, cadmium and lead, increased continuously with increasing preconcentration time (until $300 \mathrm{~s}$ ) and Bi concentration (up to $400 \mu \mathrm{g} \mathrm{L}{ }^{-1}$ ), and then saturated (Supplementary Materials Figure S6C,D). Therefore, these conditions were selected for heavy metal sensing.

\subsection{Simultaneous Detection of Cadmium and Lead, Using the HPC Electrode}

Based on the in situ formation of the bismuth alloy and the acquisition of the current signal by SWASV, cadmium and lead were detected simultaneously at various concentrations $\left(0-200 \mu \mathrm{g} \mathrm{L}^{-1}\right)$, using HPC electrodes. Distinct peak currents in the ranges of -0.7 to $-0.8 \mathrm{~V}$ and -0.45 to $-0.55 \mathrm{~V}$ were obtained from cadmium and lead, respectively, as shown in Figure 7A. A shift in the peak potential was observed upon varying the heavy metal concentrations. Nevertheless, the peak potentials from cadmium and lead in the concentration range of 0 to $200 \mu \mathrm{g} \mathrm{L}^{-1}$ could be clearly distinguished. Further, the peak current signals from the SWASV results (Figure 7A) were plotted as a function of the heavy metal concentration to analyze the performance of the HPC electrode-based heavy metal sensors, as represented in Figure 7B,C. The sensor showed a linear relationship between the peak current signal and concentration over a wide range of the heavy metal concentration $\left(0-200 \mu \mathrm{g} \mathrm{L}^{-1}\right)$. Thus, the reliability of the sensor in the detection of cadmium and lead was evaluated by using a linear regression line. The HPC electrode showed a linear correlation with good $R^{2}$ value (cadmium: 0.996, lead: 0.990) over the entire concentration range, facilitating excellent LOD (cadmium: $0.41 \mu \mathrm{g} \mathrm{L}^{-1}$, lead: $0.7 \mu \mathrm{g} \mathrm{L}-1, \mathrm{~S} / \mathrm{N}=3$ ). The LOD values were calculated based on the linear regression line of the current signals at various heavy metal concentrations, as described in Equation (2):

$$
\mathrm{LOD}=\mathrm{a}+3 \mathrm{~S}_{\mathrm{a}}
$$

where $a$ is the $y$-intercept, and $S_{a}$ is the standard deviation of the y-intercept [45]. These LOD values are much lower than the EPA standard for drinking water (cadmium: $5 \mu \mathrm{g} \mathrm{L}^{-1}$, lead: $15 \mu \mathrm{g} \mathrm{L}^{-1}$ ) [2]. Such detection of cadmium and lead at very low concentrations, using 
the small-sized electrode $\left(0.1256 \mathrm{~mm}^{2}\right)$, was enabled by the high sensitivity per unit sensing area (cadmium: $109.45 \mathrm{nA} \mathrm{\mu g}^{-1} \mathrm{~L} \mathrm{~mm}^{-2}$, lead: $100.37 \mathrm{nA} \mathrm{\mu g}^{-1} \mathrm{~L} \mathrm{~mm}^{-2}$ ), owing to the good surface reactivity and large active site area of the hierarchical sponge-like edge structures.

(A)

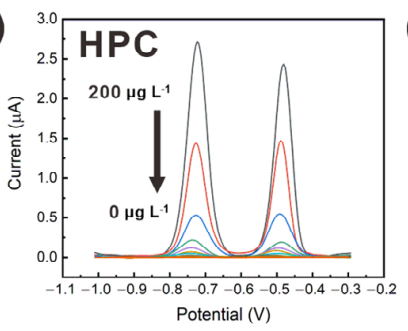

(B)

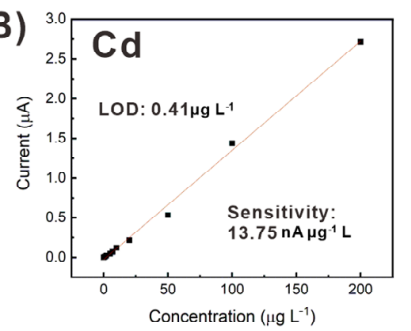

(C)

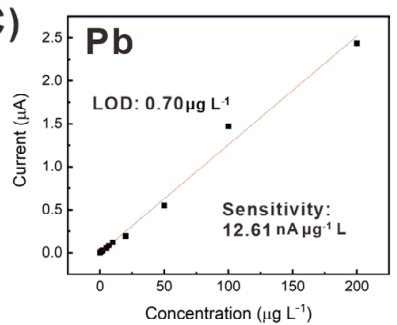

Figure 7. (A) SWASV plots obtained at various concentrations (0, 1, 2, 5, 7, 10, 20, 50, 100, and $200 \mu \mathrm{g} \mathrm{L}^{-1}$ ) of cadmium and lead in a NaAc buffer, and peak current signals at various concentrations of (B) cadmium and (C) lead measured by using a $400 \mu \mathrm{m}$ diameter disk HPC electrode.

To investigate the applicability of the present heavy metal sensor based on HPC to practical applications, the reproducibility and long-term stability were tested. Five different HPC electrodes were prepared, and their electrochemical current signals of $200 \mathrm{ppb}$ of $\mathrm{Cd}$ and $\mathrm{Pb}$ were measured once a month over two months. As shown in Figure 8, the sensors exhibited a relatively good reproducibility of $7.8 \%$ RSD, when comparing the sensor signals between sensors. In addition, the current signal from sensors exhibited a slight deviation of $6.6 \%$ RSD when the sensors were reused after each one-month storage at atmospheric conditions.

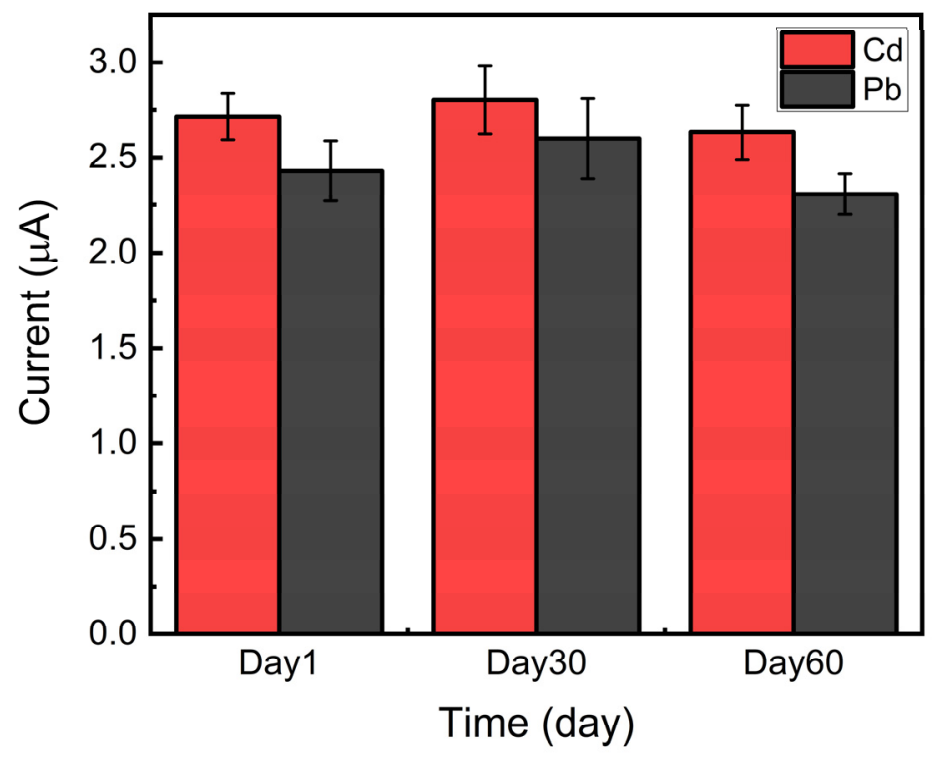

Figure 8. Reproducibility and stability test, using five different HPC electrodes for a two-month period (red bar, $200 \mathrm{ppb} \mathrm{Cd}$; black bar, $200 \mathrm{ppb} \mathrm{Pb}$ ).

The selectivity of the HPC-based heavy metal sensor was evaluated in the presence of other potentially interfering metal ions and inorganic anions, such as $\mathrm{Cu}, \mathrm{Zn}, \mathrm{Ca}, \mathrm{Fe}, \mathrm{Na}$, and $\mathrm{Cl}$. Tap water in Ulsan, South Korea, was reported to contain negligible amounts of $\mathrm{Cd}$, $\mathrm{Pb}, \mathrm{Cu}$, and $\mathrm{Fe}$, and $41.5 \mathrm{ppm}$ of chloride ion, according to the accredited test result of Korea Laboratory Accreditation Scheme, which was signed by the ILAC-MRA. In addition, we confirmed that negligible amounts of $\mathrm{Cd}, \mathrm{Pb}, \mathrm{Cu}$, and $\mathrm{Fe}$ were contained in the tap-water sample, using ICP-MS, as shown in Supplementary Materials Table S1. Thus, in this study, the peak current signals of $20 \mathrm{ppb}$ cadmium and lead were measured with the presence of $100 \mathrm{ppb} \mathrm{Zn}, \mathrm{Ca}, \mathrm{Cu}$, and Fe, as shown in Figure 9A. This test was also performed with 
excessive amounts of $\mathrm{Ca}$ and $\mathrm{Zn}(20 \mathrm{ppm})$. In the presence of $\mathrm{Zn}$ and $\mathrm{Ca}$, the current signals of $\mathrm{Cd}$ and $\mathrm{Pb}$ changed to less than 3.2 and $6.7 \%$. In contrast, $\mathrm{Cu}$ and Fe induced comparably larger signal change. However, this relatively large signal change (Cd: $\sim 18 \%, \mathrm{~Pb}: \sim 40 \%$ ) corresponds to only 2.9 and $6.2 \mathrm{ppb}$ difference in $\mathrm{Cd}$ and $\mathrm{Pb}$ detection, respectively, owing to the high sensitivity of the HPC-based sensor. The effect of $\mathrm{NaCl}$ on the heavy metal detection was also evaluated by measuring the peak currents of $\mathrm{Pb}$ and $\mathrm{Cd}$, in the presence of various concentrations of $\mathrm{NaCl}$ and the mixture of $1000 \mathrm{ppm} \mathrm{NaCl}$ and $1000 \mathrm{ppb}$ metal ions $(\mathrm{Zn}, \mathrm{Ca}, \mathrm{Cu}, \mathrm{Fe})$, as shown in Figure 9B. The organic anion also exhibited minor change in $\mathrm{Cd}$ and $\mathrm{Pb}$ detection by 1.7 and $0.7 \mathrm{ppb}$, respectively. Considering that $\mathrm{Cu}$ and $\mathrm{Fe}$ are contained in the tap water less than $100 \mathrm{ppb}$, the presented heavy metal sensor showed acceptable selectivity for the detection of $\mathrm{Cd}$ and $\mathrm{Pb}$ ions in the presence of the various interfering metal and inorganic ions.

(A)

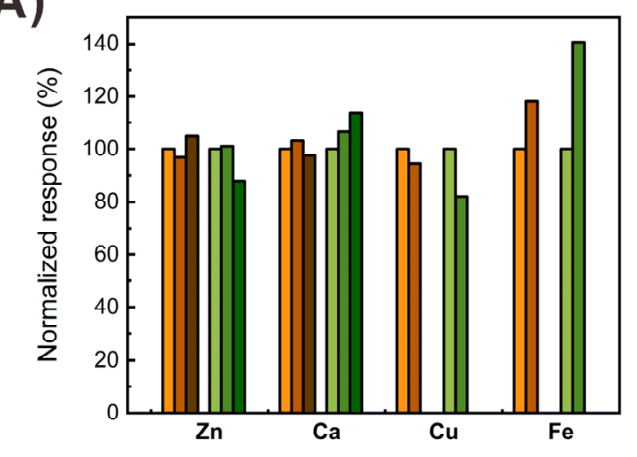

(B)

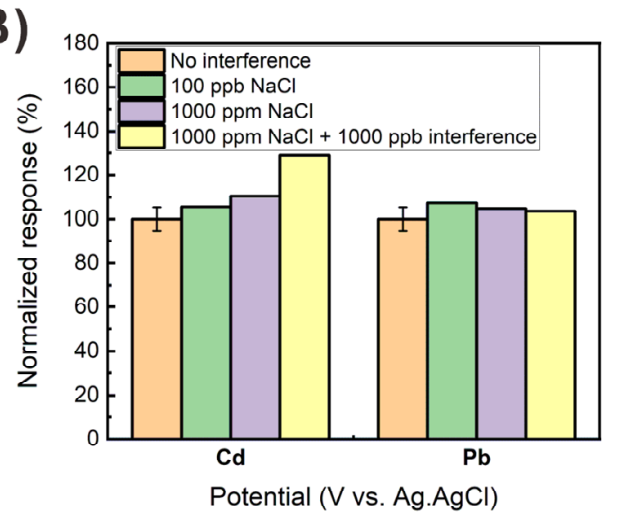

Figure 9. Interference effect on the heavy metal detection of the HPC-based heavy metal sensor: (A) normalized peak current signals of $20 \mathrm{ppb} \mathrm{Cd}$ (brown color) and $\mathrm{Pb}$ (green color) against metal ion interferences ( $\mathrm{Zn}, \mathrm{Ca}, \mathrm{Cu}$, and $\mathrm{Fe}$ ) of 100 and 20 ppm; (B) normalized peak current signals of $20 \mathrm{ppb}$ $\mathrm{Cd}$ (left bars) and $\mathrm{Pb}$ (right bars) against $\mathrm{NaCl}$ and $\mathrm{NaCl}$ with metal ion interferences ( $\mathrm{Zn}, \mathrm{Ca}, \mathrm{Cu}$, and $\mathrm{Fe}$ ).

\subsection{Heavy Metal Detection in a Real Water Sample}

The performance of the HPC-based heavy metal sensor in the analysis of real water sample was evaluated, using tap water. For the comparative correlation study, the real samples with addition of $\mathrm{Cd}$ and $\mathrm{Pb}$ were analyzed, using both ICP-MS and HPC electrodes. The HPC electrode showed good agreement with the ICP-MS results with relative errors less than $7 \%$ as shown in Table 1 . The \%RSD values of the measurement using the HPC electrode were greater, compared to ICP-MS. However, considering the EPA standard (Cd $5 \mathrm{ppb}$ and $\mathrm{Pb} 15 \mathrm{ppb}$ ), it is considered acceptable for testing tap-water samples. Supplementary Materials Figure S7 shows the SWASV curves of the HPC electrode obtained from a tapwater sample spiked with cadmium and lead at known concentrations. Peak current signals obtained from tap-water samples spiked with $0-100 \mu \mathrm{g} \mathrm{L}{ }^{-1}$ cadmium and lead are shown in Figure 10. For the linear regression, the mean values of the peak currents measured using five different HPC-based sensors were used. The linear fitting curves show relatively good $R^{2}$ values of 0.921 and 0.9757 for cadmium and lead, respectively, but the sensitivity of the HPC-based sensor was lower for the tap water, compared to that for deionized water-based samples (Figure 7B,C). However, the HPC-based sensor exhibited sufficient LOD (cadmium: $2.72 \mu \mathrm{g} \mathrm{L}^{-1}$, lead: $3.98 \mu \mathrm{g} \mathrm{L}^{-1}$ ) in the analysis of the real tap-water sample, to enable the detection of metal ions, at concentrations as low as the EPA standard for drinking water. 
Table 1. $\mathrm{Cd}$ and $\mathrm{Pb}$ concentrations in tap-water samples spiked with standard heavy metal solutions measured, using ICP-MS and HPC electrodes.

\begin{tabular}{ccccccccc}
\hline & \multicolumn{2}{c}{ ICP-MS } & \multicolumn{3}{c}{ HPC Electrode } \\
\hline Analyte & $\begin{array}{c}\text { Added } \\
\left(\mu \mathrm{g} \mathrm{L}^{-\mathbf{1}}\right)\end{array}$ & $\begin{array}{c}\text { Found } \\
\left(\mu \mathbf{g ~ L}^{-\mathbf{1}}\right)\end{array}$ & Recovery & Analyte & $\begin{array}{c}\text { Added } \\
\left(\mu \mathbf{g ~ L}^{-\mathbf{1}}\right)\end{array}$ & $\begin{array}{c}\text { Found } \\
\left(\mu \mathbf{g ~ L}^{-\mathbf{1}}\right)\end{array}$ & $\begin{array}{c}\text { Relative } \\
\text { Error (\%) }\end{array}$ \\
\hline $\mathrm{Cd}$ & 5 & $6.11 \pm 0.14$ & 122.2 & $\mathrm{Cd}$ & 5 & $5.70 \pm 0.68$ & 114 & 6.7 \\
$\mathrm{~Pb}$ & 5 & $4.53 \pm 0.19$ & 90.6 & $\mathrm{~Pb}$ & 5 & $4.26 \pm 0.20$ & 85.2 & 6.0 \\
$\mathrm{Cd}$ & 50 & $51.94 \pm 0.19$ & 103.9 & $\mathrm{Cd}$ & 50 & $48.36 \pm 4.59$ & 96.7 & 6.9 \\
$\mathrm{~Pb}$ & 50 & $46.09 \pm 0.173$ & 92.2 & $\mathrm{~Pb}$ & 50 & $58.42 \pm 3.68$ & 116.8 & 6.3 \\
\hline
\end{tabular}

(A)

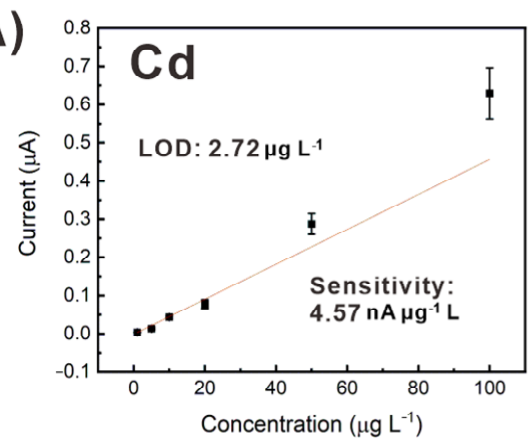

(B)

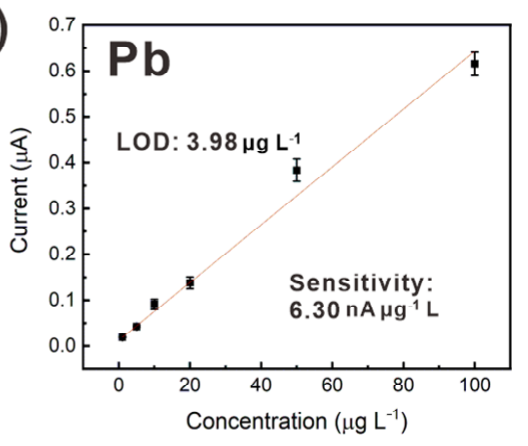

Figure 10. SWASV peak current signals from a real tap-water sample spiked with (A) cadmium and (B) lead at various concentrations $\left(0,1,5,10,20,50\right.$, and $\left.100 \mu \mathrm{g} \mathrm{L}^{-1}\right)$, obtained by using the HPC-based heavy metal sensor.

\section{Conclusions}

In this study, a sensitive heavy metal sensor was developed based on a micrometerscale sponge-like hierarchical nanoporous carbon electrode. The recently developed electrochemical heavy metal sensors have employed various types of nanostructured electrodes with large surface area and excellent surface reactivity, facilitating the detection of heavy metals at low concentrations $(0.2 \sim 20 \mathrm{ppb})$, as listed in Table 2. However, these sensors did not exhibit sufficient sensitivity per unit sensing area, to enable stable current signal measurement with a miniaturized sensor. The presented HPC electrode-based heavy metal sensor exhibited high sensitivity and low LOD at a small electrode size. This was facilitated by the sponge-like edge structure, which allows conformal and dense preconcentration of the heavy metal alloy, in addition to the large surface area and efficient electron transfer rate of the electrode. Thus, the HPC electrode showed superior sensitivity per unit sensing

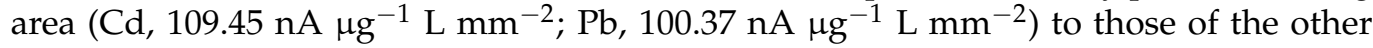
nanoporous electrode-based heavy metal sensors (Table 2). Furthermore, the LOD (Cd: $\left.2.72 \mu \mathrm{g} \mathrm{L}^{-1}, \mathrm{~Pb}: 3.98 \mu \mathrm{g} \mathrm{L}^{-1}\right)$ and sensing range $\left(0.5-200 \mu \mathrm{g} \mathrm{L}^{-1}\right)$ of the present heavy metal sensor with a micrometer-sized electrode are comparable to those of other heavy metal sensors, satisfying the EPA standard for drinking water. Moreover, HPC electrodes were successfully fabricated at a wafer-scale, using only batch microfabrication methods including C-MEMS and $\mathrm{O}_{2}$ plasma etching. This simple manufacturing process is compatible with other MEMS fabrication technologies that facilitate the integration of counter and reference electrodes for the cost-effective production of miniaturized heavy metal sensors. 
Table 2. Summary of the sensing performances of various heavy metal sensors, using SWASV method.

\begin{tabular}{|c|c|c|c|c|c|c|c|}
\hline Electrode Material & Heavy Metal & $\begin{array}{l}\text { LOD } \\
(\mathrm{ppb})\end{array}$ & $\begin{array}{c}\text { Sensing Range } \\
(\mathrm{ppb})\end{array}$ & $\begin{array}{c}{ }^{*} \text { Sensitivity } \\
\text { per Unit Sensing Area } \\
\left(\mathrm{nA} \mathrm{ppb}^{-1} \mathrm{~mm}^{-2}\right)\end{array}$ & $\begin{array}{c}\text { Electrode } \\
\text { Size }\left(\mathrm{mm}^{2}\right)\end{array}$ & Real Sample & Reference \\
\hline \multirow{2}{*}{$\left(\mathrm{Fe}_{3} \mathrm{O}_{4} / \mathrm{TA}\right) \mathrm{NPs}$ modified GCE } & $\mathrm{Cd}$ & 22.48 & $44.96-123.7$ & 5.508 & \multirow{2}{*}{19.625} & \multirow{2}{*}{ River water } & \multirow{2}{*}[46]{} \\
\hline & $\mathrm{Pb}$ & 8.29 & $82.88-227.9$ & 2.105 & & & \\
\hline \multirow{2}{*}{$\mathrm{TiO}_{2}$ nanocrystals modified GCE } & $\mathrm{Cd}$ & - & $22.48-112.4$ & 21.646 & \multirow{2}{*}{-} & \multirow{2}{*}{ River water } & \multirow{2}{*}{ [47] } \\
\hline & $\mathrm{Pb}$ & - & $41.44-207.2$ & 20.131 & & & \\
\hline $\begin{array}{c}\text { rGO/CNT/ } \\
\text { Bismuth composite }\end{array}$ & $\mathrm{Pb}$ & 0.2 & $20-200$ & 9.26 & 1.5 & Drinking water & [48] \\
\hline \multirow{2}{*}{ SWCNHs modified SPE } & $\mathrm{Cd}$ & 0.2 & $1-60$ & 0.114 & \multirow{2}{*}{7} & \multirow{2}{*}{ Milk, Honey } & \multirow{2}{*}{ [49] } \\
\hline & $\mathrm{Pb}$ & 0.4 & $1-60$ & 0.041 & & & \\
\hline \multirow{2}{*}{ AuNPs/BiNPsmodified CE } & $\mathrm{Cd}$ & 1.51 & $100-300$ & 18.338 & \multirow{2}{*}{10} & \multirow{2}{*}{ Solution in cup } & \multirow{2}{*}{ [15] } \\
\hline & $\mathrm{Pb}$ & 2.20 & $50-300$ & 15.31 & & & \\
\hline Functionalizedgold electrode & $\mathrm{Pb}$ & 0.315 & $1-400$ & - & 12.56 & Tap water & {$[50]$} \\
\hline Kelp-derived porous carbon electrode & $\mathrm{Pb}$ & 2.36 & $2.07-103.6$ & 36.48 & 7.065 & Tap water & [28] \\
\hline \multirow{2}{*}{ HPC } & $\mathrm{Cd}$ & 0.41 & $0.5-200$ & 109.45 & \multirow{2}{*}{0.1256} & \multirow{2}{*}{ Tap water } & \multirow{2}{*}{ This work } \\
\hline & $\mathrm{Pb}$ & 0.7 & $0.5-200$ & 100.37 & & & \\
\hline
\end{tabular}

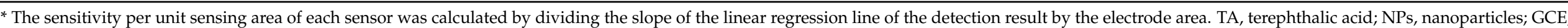
glassy carbon electrode; rGO, reduced graphene oxide; CNT, carbon nano tube; SWCNHs, single-walled carbon nanohorns; SPE, screen-printed electrode; CE, carbon electrode; LOD, limit of detection. 
Supplementary Materials: The following are available online, at https://www.mdpi.com/1424-822 0/21/4/1346/s1. Figure S1: Cyclic voltammograms of (A) bare carbon (BC), (B) porous carbon (PC), and $(C)$ hierarchical porous carbon (HPC) electrodes in $0.2 \mathrm{M} \mathrm{K}_{2} \mathrm{SO}_{4}$ at different scan rates. Figure S2: (A) SEM image and (B-D) EDS mapping of a BC electrode with electrodeposited heavy metal alloys (Cd, $10 \mathrm{mg} \mathrm{L}^{-1} ; \mathrm{Pb}, 10 \mathrm{mg} \mathrm{L}^{-1} ; \mathrm{Bi}, 400 \mu \mathrm{g} \mathrm{L}^{-1}$ ). Figure S3: (A) SEM image and (B-D) EDS mapping of a PC electrode with electrodeposited heavy metal alloys $\left(\mathrm{Cd}, 10 \mathrm{mg} \mathrm{L}^{-1} ; \mathrm{Pb}, 10 \mathrm{mg} \mathrm{L}^{-1}\right.$; $\mathrm{Bi}, 400 \mu \mathrm{g} \mathrm{L}^{-1}$ ). Figure S4: (A) SEM image and (B-D) EDS mapping of an HPC electrode with electrodeposited heavy metal alloys $\left(\mathrm{Cd}, 10 \mathrm{mg} \mathrm{L}^{-1} ; \mathrm{Pb}, 10 \mathrm{mg} \mathrm{L}^{-1} ; \mathrm{Bi}, 400 \mu \mathrm{g} \mathrm{L}^{-1}\right)$. Figure S5: XPS spectrum of BC, PC, and HPC electrodes in (A) C1s and (B) O1s regions. Figure S6: Anodic stripping peak current responses of $50 \mu \mathrm{g} \mathrm{L}^{-1}$ cadmium (black line) and $50 \mu \mathrm{g} \mathrm{L}^{-1}$ lead (red line) in SWASV under different preconcentration conditions: (A) $\mathrm{pH}$, (B) preconcentration potential, (C) preconcentration time, and (D) Bi concentration. Figure S7: SWASV curves obtained at various concentrations $\left(0,1,5,10,20,50\right.$, and $\left.100 \mu \mathrm{g} \mathrm{L}^{-1}\right)$ of cadmium and lead spiked in tap water buffered with a NaAc solution, using the HPC-based heavy metal sensor. Table S1: ICP-MS analysis of tap-water samples.

Author Contributions: Conceptualization, J.L.; investigation, J.L.; optimization, S.K.; validation, J.L. and S.K.; formal analysis, J.L.; writing—original draft preparation, J.L.; writing—review and editing, H.S.; supervision, H.S.; project administration, H.S.; funding acquisition, H.S. All authors have read and agreed to the published version of the manuscript.

Funding: This research was supported by Basic Science Research Program through the National Research Foundation of Korea(NRF) funded by the Ministry of Science and ICT (2016R1A2B4010031, 2020R1F1A1065132) and the Ministry of Education (2020R1A6A1A03040570), and Institute of Information \& communications Technology Planning \& Evaluation (IITP) grant funded by the Korea government(MSIT) (No. 2018-0-00756).

Institutional Review Board Statement: Not applicable.

Informed Consent Statement: Not applicable.

Data Availability Statement: The data presented in this study are available on request from the corresponding author.

Acknowledgments: We are grateful for technical assistance from the staff members at UCRF, in UNIST.

Conflicts of Interest: The authors declare no conflict of interest.

\section{References}

1. Aragay, G.; Pons, J.; Merkoci, A. Recent trends in macro-, micro-, and nanomaterial-based tools and strategies for heavy-metal detection. Chem. Rev. 2011, 111, 3433-3458. [CrossRef]

2. US Environmental Protection Agency. Seminar Publication: Risk Assessment, Management and Communication of Drinking Water Contamination; National Service Center for Environmental Publications: Cincinnati, OH, USA, 1989.

3. Habila, M.A.; ALOthman, Z.A.; El-Toni, A.M.; Labis, J.P.; Soylak, M. Synthesis and application of $\mathrm{Fe}_{3} \mathrm{O}_{4} @ \mathrm{SiO}_{2} @ \mathrm{TiO}_{2}$ for photocatalytic decomposition of organic matrix simultaneously with magnetic solid phase extraction of heavy metals prior to ICP-MS analysis. Talanta 2016, 154, 539-547. [CrossRef]

4. Narin, İ.; Soylak, M.; Elçi, L.; Doğan, M. Determination of trace metal ions by AAS in natural water samples after preconcentration of pyrocatechol violet complexes on an activated carbon column. Talanta 2000, 52, 1041-1046. [CrossRef]

5. Marguí, E.; Zawisza, B.; Sitko, R. Trace and ultratrace analysis of liquid samples by X-ray fluorescence spectrometry. TrAC Trends Anal. Chem. 2014, 53, 73-83. [CrossRef]

6. Rex, M.; Hernandez, F.E.; Campiglia, A.D. Pushing the limits of mercury sensors with gold nanorods. Anal. Chem. 2006, 78, 445-451. [CrossRef]

7. Wagner, K.A.; Levine, K.E.; Jones, B.T. A simple, low cost, multielement atomic absorption spectrometer with a tungsten coil atomizer. Spectrochim. Acta Part B 1998, 53, 1507-1516. [CrossRef]

8. Waggoner, J.W.; Milstein, L.S.; Belkin, M.; Sutton, K.L.; Caruso, J.A.; Fannin, H.B. Application of a low power/reduced pressure helium ICP ionization source for mass spectrometric detection of organobromine compounds and derivatized organotin compounds. J. Anal. At. Spectrom. 2000, 15, 13-18. [CrossRef]

9. Zhou, S.; Yuan, Z.; Cheng, Q.; Zhang, Z.; Yang, J. Rapid in situ determination of heavy metal concentrations in polluted water via portable XRF: Using $\mathrm{Cu}$ and $\mathrm{Pb}$ as example. Environ. Pollut. 2018, 243, 1325-1333. [CrossRef] [PubMed]

10. Barton, J.; García, M.B.G.; Santos, D.H.; Fanjul-Bolado, P.; Ribotti, A.; McCaul, M.; Diamond, D.; Magni, P. Screen-printed electrodes for environmental monitoring of heavy metal ions: A review. Microchim. Acta 2016, 183, 503-517. [CrossRef] 
11. Braga, M.S.; Jaimes, R.F.; Borysow, W.; Gomes, O.F.; Salcedo, W.J. Portable multispectral colorimeter for metallic ion detection and classification. Sensors 2017, 17, 1730. [CrossRef] [PubMed]

12. Sriram, G.; Bhat, M.P.; Patil, P.; Uthappa, U.T.; Jung, H.Y.; Altalhi, T.; Kurkuri, M.D. Paper-based microfluidic analytical devices for colorimetric detection of toxic ions: A review. TrAC Trends Anal. Chem. 2017, 93, 212-227. [CrossRef]

13. Gan, Y.; Liang, T.; Hu, Q.; Zhong, L.; Wang, X.; Wan, H.; Wang, P. In-situ detection of cadmium with aptamer functionalized gold nanoparticles based on smartphone-based colorimetric system. Talanta 2020, 208, 120231. [CrossRef]

14. Li, M.; Li, D.W.; Li, Y.T.; Xu, D.K.; Long, Y.T. Highly selective in situ metal ion determination by hybrid electrochemical "adsorption-desorption" and colorimetric methods. Anal. Chim. Acta 2011, 701, 157-163. [CrossRef] [PubMed]

15. Xu, G.; Li, X.; Cheng, C.; Yang, J.; Liu, Z.; Shi, Z.; Liu, Q. Fully integrated battery-free and flexible electrochemical tag for on-demand wireless in situ monitoring of heavy metals. Sens. Actuators B Chem. 2020, 310, 127809. [CrossRef]

16. Yi, W.J.; Li, Y.; Ran, G.; Luo, H.Q.; Li, N.B. Determination of cadmium (II) by square wave anodic stripping voltammetry using bismuth-antimony film electrode. Sens. Actuators B Chem. 2012, 166, 544-548. [CrossRef]

17. Li, M.; Gou, H.; Al-Ogaidi, I.; Wu, N. Nanostructured sensors for detection of heavy metals: A review. ACS Sustain. Chem. Eng. 2013, 1, 713-723. [CrossRef]

18. Vyskočil, V.; Barek, J. Mercury electrodes-possibilities and limitations in environmental electroanalysis. Crit. Rev. Anal. Chem. 2009, 39, 173-188. [CrossRef]

19. Daniele, S.; Bragato, C.; Baldo, M.A.; Ciani, I. Application of thin-shielded mercury microelectrodes in anodic stripping voltammetry. Talanta 2008, 77, 235-240. [CrossRef]

20. Wang, J. Stripping analysis at bismuth electrodes: A review. Electroanalysis 2005, 17, 1341-1346. [CrossRef]

21. Zou, Z.; Jang, A.; Macknight, E.; Wu, P.M.; Do, J.; Bishop, P.L.; Ahn, C.H. Environmentally friendly disposable sensors with microfabricated on-chip planar bismuth electrode for in situ heavy metal ions measurement. Sens. Actuators B Chem. 2008, 134, 18-24. [CrossRef]

22. Zhang, C.H.; Li, G.-J.; Wang, J.-H. Application of nanopore and porous materials for heavy metal ion detection. Chin. J. Anal. Chem. 2014, 42, 607-615. [CrossRef]

23. Kim, S.; Dong, W.J.; Gim, S.; Sohn, W.; Park, J.Y.; Yoo, C.J.; Jang, H.W.; Lee, J.L. Shape-controlled bismuth nanoflakes as highly selective catalysts for electrochemical carbon dioxide reduction to formate. Nano Energy 2017, 39, 44-52. [CrossRef]

24. Zhu, C.; Li, H.; Fu, S.; Du, D.; Lin, Y. Highly efficient nonprecious metal catalysts towards oxygen reduction reaction based on three-dimensional porous carbon nanostructures. Chem. Soc. Rev. 2016, 45, 517-531. [CrossRef] [PubMed]

25. Sun, J.; Li, M.; Zhang, Z.; Guo, J. Unravelling the adsorption disparity mechanism of heavy-metal ions on the biomass-derived hierarchically porous carbon. Appl. Surf. Sci. 2019, 471, 615-620. [CrossRef]

26. Yuan, X.; An, N.; Zhu, Z.; Sun, H.; Zheng, J.; Jia, M.; Liu, N. Hierarchically porous nitrogen-doped carbon materials as efficient adsorbents for removal of heavy metal ions. Process. Saf. Environ. Prot. 2018, 119, 320-329. [CrossRef]

27. Li, J.; Liu, K.; Gao, X.; Yao, B.; Huo, K.; Cheng, Y.; Ding, D. Oxygen-and nitrogen-enriched 3D porous carbon for supercapacitors of high volumetric capacity. ACS Appl. Mater. Interfaces 2015, 7, 24622-24628. [CrossRef]

28. Guan, J.; Fang, Y.; Zhang, T.; Wang, L.; Zhu, H.; Du, M.; Zhang, M. Kelp-Derived Activated Porous Carbon for the Detection of Heavy Metal Ions via Square Wave Anodic Stripping Voltammetry. Electrocatalysis 2020, 11, 59-67. [CrossRef]

29. Wang, C.; Madou, M. From MEMS to NEMS with carbon. Biosens. Bioelectron. 2005, 20, 2181-2187. [CrossRef]

30. Kostecki, R.; Schnyder, B.; Alliata, D.; Song, X.; Kinoshita, K.; Kötz, R. Surface studies of carbon films from pyrolyzed photoresist. Thin Solid Films 2001, 396, 36-43. [CrossRef]

31. Sharma, S. Glassy carbon: A promising material for micro-and nanomanufacturing. Materials 2018, 11, 1857. [CrossRef]

32. VanDersarl, J.J.; Mercanzini, A.; Renaud, P. Integration of 2D and 3D thin film glassy carbon electrode arrays for electrochemical dopamine sensing in flexible neuroelectronic implants. Adv. Funct. Mater. 2015, 25, 78-84. [CrossRef]

33. Sharma, D.; Lee, J.; Seo, J.; Shin, H. Development of a Sensitive Electrochemical Enzymatic Reaction-Based Cholesterol Biosensor Using Nano-Sized Carbon Interdigitated Electrodes Decorated with Gold Nanoparticles. Sensors 2017, 17, 2128. [CrossRef] [PubMed]

34. Mohamed Hassan, Y.; Caviglia, C.; Hemanth, S.; Mackenzie, D.M.A.; Petersen, D.H.; Keller, S.S. Pyrolytic carbon microelectrodes for impedance based cell sensing. ECS Trans. 2016, 72, 35-44. [CrossRef]

35. Thiha, A.; Ibrahim, F.; Muniandy, S.; Dinshaw, I.J.; Teh, S.J.; Thong, K.L.; Leo, B.F.; Madou, M. All-carbon suspended nanowire sensors as a rapid highly-sensitive label-free chemiresistive biosensing platform. Biosens. Bioelectron. 2018, 107, 145-152. [CrossRef]

36. Mardegan, A.; Kamath, R.; Sharma, S.; Scopece, P.; Ugo, P.; Madou, M. Optimization of Carbon Electrodes Derived from Epoxy-based Photoresist. J. Electrochem. Soc. 2013, 160, B132-B137. [CrossRef]

37. Du, K.; Wathuthanthri, I.; Liu, Y.; Kang, Y.T.; Choi, C. Fabrication of polymer nanowires via maskless $\mathrm{O}_{2}$ plasma etching. Nanotechnology 2014, 25, 165301. [CrossRef]

38. Lim, Y.; Woo, J.; Joo, S.H.; Shin, H. Patternable nanoporous carbon electrodes for use as supercapacitors. J. Electrochem. Soc. 2016, 163, A1886. [CrossRef]

39. Lim, Y.; Chu, J.H.; Kwon, S.Y.; Shin, H. Increase in graphitization and electrical conductivity of glassy carbon nanowires by rapid thermal annealing. J. Alloys Compd. 2017, 702, 465-471. [CrossRef] 
40. Tsougeni, K.; Vourdas, N.; Tserepi, A.; Gogolides, E. Mechanisms of Oxygen Plasma Nanotexturing of Organic Polymer Surfaces: From Stable Super Hydrophilic to Super Hydrophobic Surfaces. Langmuir 2009, 25, 11748-11759. [CrossRef]

41. Deng, H.; Zhang, C.; Xie, Y.; Tumlin, T.; Giri, L.; Karna, S.P.; Lin, J. Laser induced MoS 2/carbon hybrids for hydrogen evolution reaction catalysts. J. Mater. Chem. A 2016, 4, 6824-6830. [CrossRef]

42. Łukaszewski, M.; Soszko, M.; Czerwiński, A. Electrochemical methods of real surface area determination of noble metal electrodes-An overview. Int. J. Electrochem. Sci. 2016, 11, 4442-4469. [CrossRef]

43. Park, S.; Song, Y.J.; Han, J.H.; Boo, H.; Chung, T.D. Structural and electrochemical features of 3D nanoporous platinum electrodes. Electrochim. Acta 2010, 55, 2029-2035. [CrossRef]

44. Walther, F.; Davydovskaya, P.; Zürcher, S.; Kaiser, M.; Herberg, H.; Gigler, A.M.; Stark, R.W. Stability of the hydrophilic behavior of oxygen plasma activated SU-8. J. Micromech. Microeng. 2007, 17, 524. [CrossRef]

45. Stone, D.; Ellis, J. Calibration and Linear Regression Analysis: A Self-Guided Tutorial. In CHM314 Instrumental Analysis; Department of Chemistry, University of Toronto: Toronto, ON, Canada, 2003.

46. Deshmukh, S.; Kandasamy, G.; Upadhyay, R.K.; Bhattacharya, G.; Banerjee, D.; Maity, D.; Roy, S.S. Terephthalic acid capped iron oxide nanoparticles for sensitive electrochemical detection of heavy metal ions in water. J. Electroanal. Chem. 2017, 788, 91-98. [CrossRef]

47. Liao, J.; Yang, F.; Wang, C.Z.; Lin, S. The crystal facet-dependent electrochemical performance of $\mathrm{TiO}_{2}$ nanocrystals for heavy metal detection: Theoretical prediction and experimental proof. Sens. Actuators B Chem. 2018, 271, 195-202. [CrossRef]

48. Xuan, X.; Park, J.Y. A miniaturized and flexible cadmium and lead ion detection sensor based on micro-patterned reduced graphene oxide/carbon nanotube/bismuth composite electrodes. Sens. Actuators B Chem. 2018, 255, 1220-1227. [CrossRef]

49. Yao, Y.; Wu, H.; Ping, J. Simultaneous determination of Cd (II) and Pb (II) ions in honey and milk samples using a single-walled carbon nanohorns modified screen-printed electrochemical sensor. Food Chem. 2019, 274, 8-15. [CrossRef] [PubMed]

50. Wang, N.; Zhao, W.; Shen, Z.; Sun, S.; Dai, H.; Ma, H.; Lin, M. Sensitive and selective detection of Pb (II) and Cu (II) using a metal-organic framework/polypyrrole nanocomposite functionalized electrode. Sens. Actuators B Chem. 2020, $304,127286$. [CrossRef] 